\title{
Infections related to central venous catheters: which germs and what profile of resistance?
}

\author{
Ezzouine H., El Ammari I., Jerrari A., Benslama A. \\ Medical intensive care unit \\ Dept of Anaesthesiology \& Intensive Care, \\ University Hassan II Faculty of Medicine and Pharmacy, \\ Casablanca, Morocco
}

Background and Goal of Study:

This work is a retrospective descriptive and analytical study of documented infections related to the central venous catheters, spread over a period of one year, from January 2015 to December 2015, carried out in the medical intensive care unit of the Ibn Rushd Hospital in Casablanca, Morocco.

\section{Materials and Methods:}

Included were all patients with central venous catheterization, with or without bacteraemia, after hospitalization in the medical resuscitation unit of Ibn Rushd Hospital for more than 48 hours.

Results and Discussion:

-Gram negative bacilli were isolated from the culture of central venous catheters in $40.5 \%$ of cases.

-cocci Gram positive represented a rate of $35.1 \%$, -staphylococcus coagulase negative is the most frequently isolated with a rate of $84.61 \%$.

-bacilli Gram positive represent a rate of $8.2 \%$.

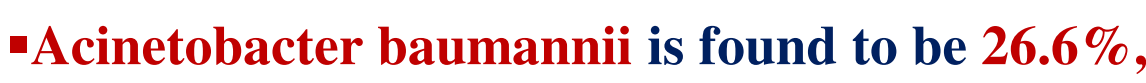
is resistant to $100 \%$ Imipenem, sensitive to Amikacin; Gentamycin, Cefepime and Netilmycin

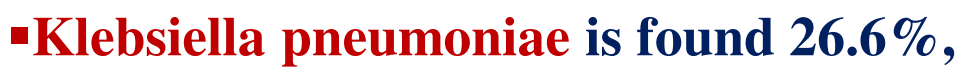

it is resistant to 75\% : Ampicillin ; Cefotaxime,

sensitive to 75\%: Imipeneme, Amikacin; Cefoxitin.

-For Proteus mirabilis,

$50 \%$ were resistant to ampicillin,cefalotine,imipeneme.

-The rate of enteric bacteria producing ESBL was $62.5 \%$.
Resistance Profile of Acinetobacter Baumanii

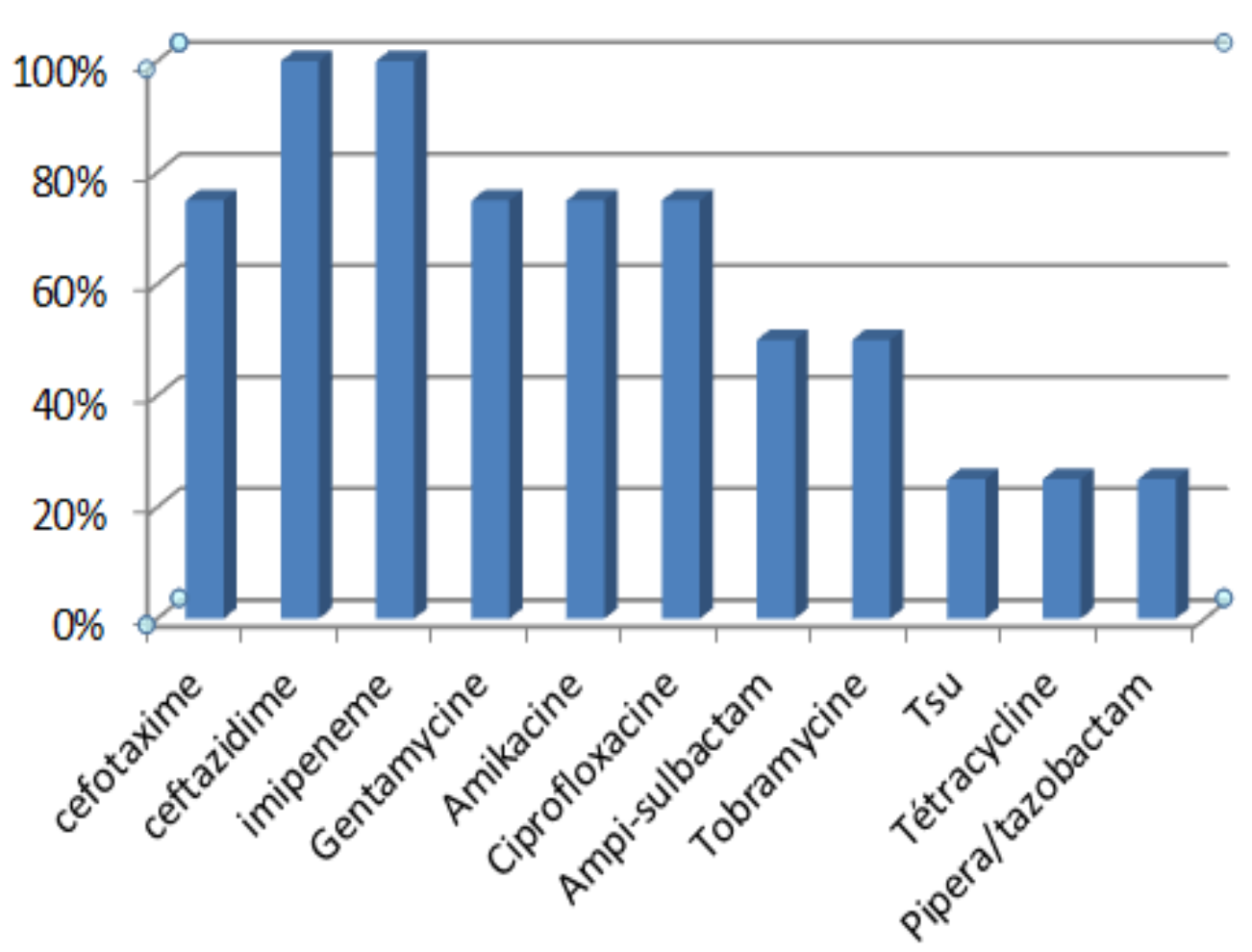

Resistance Profile of Klebsiella pneumonia

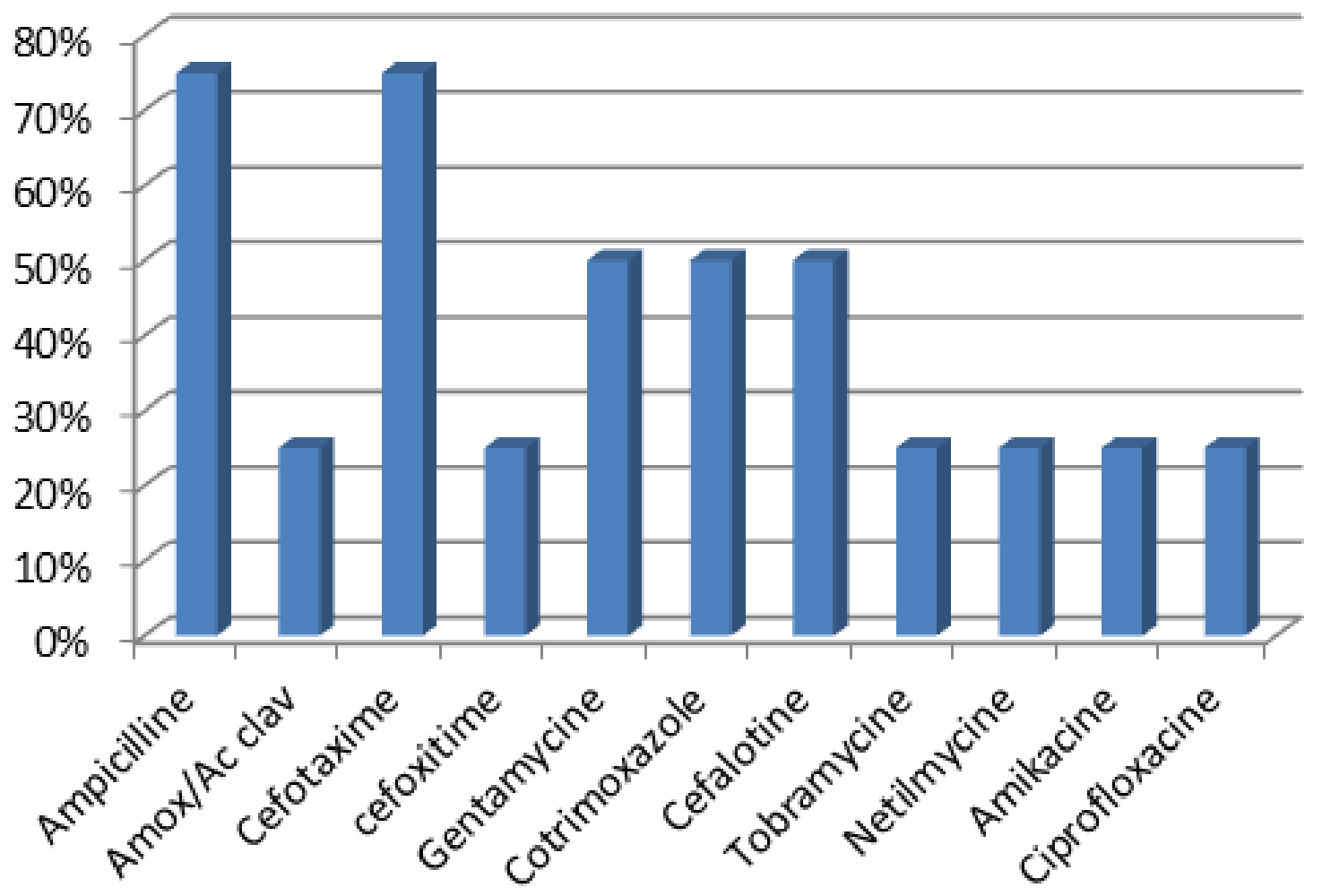

-For Pseudomonas aeruginosa,

$100 \%$ were resistant to imipenem, ceftazidime,gentamycin

Netilmycin.

-Staphylococcus coagulase negative

was resistant to Penicillin $\mathrm{G}$ with a rate of $72.7 \%$

$63.6 \%$ to kanamycin . with a sensitivity of $100 \%$ to teicoplanin.

\section{Conclusion(s):}

The main problem in intensive units are nosocomial infections .The infections related to central venous catheters are a risk and they can be due to multiresistant bacterias .

In our study, Acinetobacter baumanii is the main germ and it is resistant to imipenem in $100 \%$.

A strategy of managing antibiotherapy is essential in intensive care so are preventive measures in nursing and catheters cares. 